\title{
The role of tutor's questioning in mentoring learners' responses to and uptake of feedback on writing
}

\author{
Murad Abdu Saeed ${ }^{1}$, Atef Odeh AbuSa'aleek ${ }^{2 *}$, and Huda Suleiman Al Qunayeer ${ }^{1}$ \\ ${ }^{I}$ Department of English, English Department, Unaizah College of Sciences and Arts, Qassim University, \\ Saudi Arabia \\ ${ }^{2}$ Department of English, College of Education, Majmaah University, Al-Majmaah, 11952, Saudi Arabia.
}

\begin{tabular}{|c|c|}
\hline \multirow{2}{*}{\multicolumn{2}{|c|}{$\begin{array}{l}\text { ABSTRACT } \\
\text { How teachers can provide effective feedback that promotes' studer } \\
\text { use of it is the question of the current debate in research. } \\
\text { formulate/compose their feedback in the form of questioning allevic } \\
\text { in the process. Therefore, this study explored the role of teacher } \\
\text { given in the form of questions on the assignments of } 14 \text { pairs of unc } \\
\text { university in fostering their responses to feedback and uptake of } \\
\text { revealed that the feedback questions fall into single Yes/No question } \\
\text { a combination of both, which served as eliciting responses, elic } \\
\text { clarifications, requesting, checking certainty, and inviting learners } \\
\text { over the e-feedback before using it in revising their texts. Findings } \\
\text { functions as an interactive platform where students diversify their re } \\
\text { as commenting on the e-feedback, interacting around the e-feedb } \\
\text { feedback, resolving the e-feedback, and addressing the e-feedback } \\
\text { Furthermore, the way e-feedback questioning is formulated influenc } \\
\text { and use e-feedback in revising their assignments. The study provid } \\
\text { teacher feedback practices in graduate courses in higher educational } \\
\text { Keywords: Questioning; responses to feedback; teacher electronic } \mathrm{f} \\
\text { feedback }\end{array}$}} \\
\hline & \\
\hline & \\
\hline & \\
\hline
\end{tabular}

\section{INTRODUCTION}

University students need effective feedback to develop their competence and academic writing skills (Schillings et al., 2019; Winder et al., 2016). Being repositioned as a learner-centered process, teacher feedback is currently viewed as an interactive process in which learners should actively respond to the information, process it, and make good use of it in improving their writing (Carless, 2020; Carless \& Boud, 2018; Henderson et al., 2019; Schillings et al., 2019). As opposed to the unidirectional written feedback (Nassaji, 2011), teachers' practical and interactive feedback should allow learners to communicate their ideas, talk about the issues in their writing and interact with teachers/instructors and peers around these issues. In addition to clarifying or resolving misunderstandings and confusions, comprehend the feedback they receive and maximize their uptake in revising their texts (Carless \& Boud, 2018; Ferris, 1995; Goldstein, 2006; Storch \& Wigglesworth, 2010). Teachers are recommended to keep away from feedback formulations that emphasize their authoritative roles to provide effective feedback (e.g., imperatives), provide mere evaluations of writing (e.g., evaluative feedback), and

\footnotetext{
* Corresponding Author

Email: a.odeh@mu.edu.sa
} 
communicate their points that can be open to students' interpretations (Jonsson, 2013).

The need for teachers to formulate/compose their feedback in the form of questioning alleviates their authoritative roles in the process. It enables learners to interact with them as partners, which is also in line with Carless' (2020) current call considering a teacher-student partnership in feedback formation. Effective feedback formation should engage learners in actively responding to it (Saeed \& Al Qunayeer, 2020). Otherwise, learners may find feedback difficult to understand and apply to their writing (Saeed et al., 2021). In this regard, the use of teacher feedback in the form of questions allows learners to think carefully about the issues in their writing (Ferris, 1997), highlights limitations of knowledge, makes the force of a feedback statement weaker (Hyland \& Hyland, 2001), and initiates a form of dialogue with learners by inviting them to think and respond to it (Carless, 2020). Questioning is an effective instructional strategy that engages learners in critical thinking and constructing knowledge in classroom talks (e.g., Chen, 2006) and stimulates their responses and interactions in online learning asynchronous discussions (e.g., Schindler $\&$ Burkholder, 2014). It is also one of the significant patterns of teacher classroom feedback (e.g., Ferris, 1997; Hyland \& Hyland, 2001; William, 2004) and e-feedback (Alvarez et al., 2012; Tuzi, 2004; Wolsey, 2008).

Despite this evidence on the value of questioning as an instructional strategy in teaching practices, including feedback, how and to what extent students would respond to teacher feedback questioning and use it in revising their texts should be further explored. This research topic is important mainly because of the availability of educational technology tools varying from blogs to Google Docs that allow teachers to rethink efficient instructional strategies in composing and delivering feedback that promotes students' responses and interactions and maximizes their uptake of feedback (Chong, 2019; Cramp, 2011; Ene \& Upton, 2014; 2018). Teacher electronic (e-) feedback is defined as written commentary provided by teachers/instructors on students' written texts, using technological or software tools (AbuSeileek \& AbuAlshar, 2014; Ene \& Upton, 2014). Yet, teacher e-feedback needs to be further explored in writing instruction (Ene \& Upton, 2018). Investigation of this research topic is significant since it will provide useful insight into effective feedback formation. It will also offer valuable pedagogical implications for EFL writing teachers and instructors in enhancing their feedback practices in writing courses. Therefore, the current study sets out to identify the patterns of e-feedback questioning concerning its forms, functions, nature, and foci given by the instructor on students' assignments through Google Docs over an academic semester. Furthermore, it aims to explore students' responses to teacher's feedback questioning, including their uptake/use of feedback in revising their assignments. The study attempts to answer the following specific research questions:

1. What are the patterns of e-feedback questioning provided by the instructor on students' writing through Google Docs?

2. How does the instructor, through questioning, promote learners' responses to the e-feedback and use it in revising their assignments?

3. To what extent does the teacher's formulation of various e-feedback questioning influence students' responses to and use/uptake of e-feedback in revising their assignments?

\section{Questioning as an Effective Instructional Strategy in Feedback}

Questioning is defined as an effective instructional strategy in various feedback settings, including teacher feedback and peer feedback settings (Munje et al., 2018). Goldstein (2006) raised important questions about how teachers should formulate their feedback: whether they should ask questions, tell learners what to do, or instruct their students on what and how to revise their texts. Teachers' use of questioning has been identified as one type of teacher feedback form (e.g., Ferris, 1997; Hyland \& Hyland, 2001; William, 2004). According to Ferris (1997), despite its low impact on students' text revisions, as opposed to other forms of feedback such as direct corrections, teachers' questioning plays a role in stimulating learners' thinking processes and avoiding appropriating their written texts. While questions are intended to engage and elicit learners' responses to feedback, they are also a means to mitigate teachers' imposition of criticism on learners' writing (Hyland \& Hyland, 2001).

In William's (2004) study, teacher's use of questioning guides student-writers to identify issues and facilitates their understanding of the issues or errors in their written texts. As an interrogative form of feedback, questioning plays a role in initiating dialogues/interactions since it invites learners to think of the feedback and respond to it (Carless, 2020). Feedback questions were found to elicit students' reflection on the feedback they received and entice them to think of the feedback they would use in revising their written assignments (Duijnhouwer et al., 2012). Yet, in this latter study, the results were derived from students' mere perception, which means that learners were asked to reflect on teacher feedback after receiving it and before revising their writing rather than part of the feedback.

With the evidence from several studies (Alvarez et al., 2012; Ene \& Upton 2018; Tuzi, 2004; Wolsey, 2008) on the value of teacher e- 
feedback, questions serve different functions, including clarifications and requests for explanations (Alharbi, 2019; Alvarez et al., 2012) as well as eliciting information or responses from learners (Tuzi, 2004). Moreover, e-feedback questions promote students' responses and inquiry (Wolsey, 2008). Finally, unlike direct corrections, feedback questions play an important role in promoting students' productive responses to feedback and text revisions (Alvarez et al., 2012).

The above studies have examined feedback questioning as part of teacher feedback practices (Alharbi, 2019; Alvarez et al., 2012; Ferris 1997; Hyland \& Hyland, 2001; Tuzi, 2004; William, 2004; Wolsey, 2008). Yet, what forms of feedback questioning: Yes/No questions or Wh-questions and what functions feedback questions should perform (e.g., eliciting a response, seeking information, requesting, etc.) have not been deeply explored. These questioning functions are essential to be distinguished and further explored to determine teachers' underlying meanings or intentions conveyed through the different feedback questions (Ferris, 1997; Hyland \& Hyland, 2001).

The use of questioning has also been reported by research on peer feedback in ESL/EFL writing and student tutors' feedback in writing centers established at universities in different parts of the world to provide university students with feedback and help them in thesis writing. In peer feedback sessions, questioning used as an instructional intervention/prompt (similar to the above study of Duijnhouwer et al., 2012, on teacher feedback) helped student-authors to cognitively process peer feedback by indicating to the comments they addressed in revising their writing and learning from these comments (Gielen et al., 2010; Gielen, Tops, et al., 2010).In addition, as a form of peer feedback in university writing centers, questioning was found of two types: task-related questioning (questioning used for guiding students to focus on a current task) and writing-related questioning (questioning used for developing students' knowledge of academic writing, such as how to write a particular genre) (Munje et al., 2018). The pedagogical value of questioning in writing centers lies in its role in directing students to focus on a particular task and making them think of and prepare good answers to the questions (O’Sullivan \& Cleary, 2014).

\section{Students' Responses to Feedback}

Discussion of learners' responses to teacher feedback reflects how learners can notice errors/issues in their writing, how they react to different patterns of corrective feedback once receiving it, and the extent to which they take up/productively use corrective feedback (Alsolami \& Elyas, 2016). According to Storch and Wigglesworth (2010), learners' engagement with feedback helps us understand how learners notice their errors and subsequently produce the correct forms. Moreover, some researchers (e.g., Winstone et al., 2017; Carless \& Boud, 2018) emphasize learners' repertoire of strategies that enable them to make productive actions once receiving feedback. These researchers add that although many students appear to be aware of the issues and errors addressed through corrective feedback, they may find it challenging to act upon them or revise their writing.

Students may not productively use corrective feedback in revising their texts if they do not see themselves as active learners rather than mere receivers of feedback (Boud \& Molloy, 2013). Only a very few students may successfully act upon the feedback due to the lack of opportunity to reflect, comment on feedback and interpret it before revising their writing (Robinson et al., 2013).

There are few studies on students' responses or comments on teachers' e-corrective feedback which reveals that these responses vary from conformations, corrections (Alharbi, 2019; Alvarez et al., 2012), explanations of issues in writing (Chong, 2019), clarifications, agreements vs. disagreements with feedback as well as articulation of their misunderstandings and confusions (Alharbi, 2019), and asking questions (Chong, 2019) as well as suggestions and discussions of changes in their texts (Alvarez et al., 2012).

Yet, these studies focused on the patterns of students' single comments on teacher e-feedback rather than whether and how students would interact around e-feedback issues in responding to it. Carless (2020) stated that teacher effective feedback should engage learners in interacting with teachers to establish mutual understandings and resolve dissonances resulting from feedback. Moreover, interaction is another means to improve students' comprehension of teacher feedback (Schillings et al., 2019).

\section{Studies on Google Docs in Writing Instruction and Feedback}

Research on teacher e-feedback indicates that teachers provide e-feedback through asynchronously written comments using the commenting functions of one of these potential tools: Microsoft (MS) Word (Cunningham, 2019; Ene \& Upton, 2014; 2018; Rodina, 2008) or even Google Docs (Alharbi, 2019). Such facilitative features of MS Word and Google Docs allow teachers to provide students with lengthy, specific, and detailed feedback on their writing (Alharbi, 2019; Cunningham, 2019; Ene \& Upton, 2014; 2018; Rodina, 2008). Recently, researchers' interest in adopting Google Docs as a web-based writing facilitative tool has increased (Jeong, 2016; Suwantarathip \& Wichadee, 2014; Zhou et al., 2012). These studies indicate that Google Docs is free online software that permits EFL learners to create and edit documents online. 
Furthermore, Google Docs permits both learners to collaborate on documents online and allows teachers to provide feedback on their writings and simultaneously get responses from the learners. In other words, Jeong (2016) stated that Google Docs as the online collaborative platform allows learners to create their online documents, submit their draft, work collaboratively, share their collective knowledge, receive e--feedback from their teachers, and respond to the feedback to improve their final version of the written task and share their writing with their classmates.

Concerning students' responses to Google Docs-supported feedback, students can respond to teacher e-feedback through text revisions or changes to their written texts and written comments on their e-feedback using the reply function of Google Docs (Alharbi, 2019; Chong, 2019). Hence, Google Docs allows space for learners to reflect on feedback and interpret it. In other words, while the commenting option in Google Docs allows learners and teachers to give and respond quickly to each other and see and read such comments, the editing function of Google Docs allows learners to make changes to their written documents and highlight these changes (Suwantarathip \& Wichadee, 2014). Google Docs allows learners to edit and revise documents without restrictions (Holliman \& Scanlon, 2006; Oishi, 2007; Perron \& Sellers, 2011) and facilitates active communication and dynamic classroom interaction (Jeong, 2016).

\section{METHOD}

\section{Research Design}

The present study employed a qualitative case study, specifically an exploratory case study that suits research aiming to obtain a better understanding of a particular context (McConlogue, 2015) and particularities of a case (Stake, 1995). It has also been used to explore feedback and students' responses to feedback (Xu, 2017).

\begin{abstract}
Study Setting
The course consists of face-to-face lectures delivered by one of the researchers of this study, tutorials, online materials, including PowerPoint and tutorial or instructional videos. One of the tasks assigned to the students in this course was to develop a four-section paper: (1) introduction, (2) literature review, (3) methods, and (4) findings and conclusion based on a morpho-syntactic analysis of features and constituents of a written text on a topic of their choice concerning the course. The students had to work in pairs, so there were 14 pairs of students who worked on a paper over the semester.
\end{abstract}

\section{Participants}

The study was conducted among 28 Malaysian undergraduates: 18 females and ten males joining a course in linguistics at the English Department in a Malaysian public university. They were all local Malaysian students. The first-year university undergraduates joined the course as part of their first-year courses in the English Department. As English majoring students, they spoke English as their second language.

\section{The Peer Writing and Teacher E-Feedback Procedure}

The pair writing and e-feedback procedure consist of several steps which are part of the course followed by the instructor and undergraduate students but should not be understood as a treatment as seen in Table 1.

Table 1

The E-Feedback Activities

\begin{tabular}{ll}
\hline Time-line & Activities \\
\hline Week 1-2 & Giving instruction on the peer-written assignment/task and consent \\
Week 3 & Making pair divisions and creating Google Docs pages \\
Week 4-8 & Working on analyzing the morpho-syntactic features of the chosen \\
& written texts \\
Week 9-13 & Writing the assignments and providing feedback on the first drafts, and \\
& students were revising their drafts. \\
Week 14 & Students submitting their final drafts \\
\hline
\end{tabular}

During the first step, the undergraduates were instructed on the pair assignments in the first few weeks of the semester. They were also informed that they would work on this assignment in pairs over the semester or till the 14th week when they had to submit the final draft. Moreover, they were informed that each pair would work on their assignment through Google Docs, shared with the course instructor to provide them e-feedback. As a matter of research ethics, the instructor informed all students that while the e-feedback was meant to guide them in developing well-written assignments, it was also meant to collect data for research purposes. They also were requested to sign written consent on their participation and informed of protecting their confidentiality.

The second step was to allow undergraduates to select their partners for the pair assignments. 
Then, every two students forming a pair were requested to open a Google Docs page later shared with the instructor through his email or as an email invitation. Each pair also worked together and discussed how to analyze the selected written text via the Google Docs page. This continued till the 8th week, after which students had to start writing the first draft. Thus, by the time the data collection started in this study, the student was writing the first drafts of their assignments (1500-2000 words). This step is further illustrated in Figure (1) below.

\section{Figure 1}

The Interactive E-Feedback Process through Google Docs

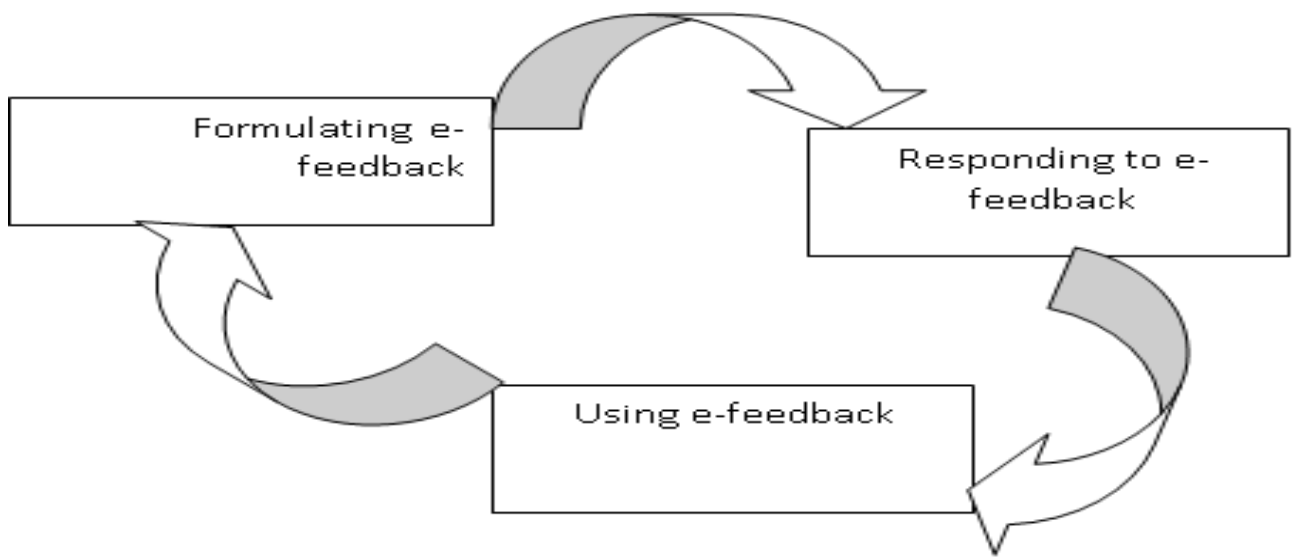

Once each pair finished a section of their assignment, the instructor provided them e-feedback (Figure 2). They were also asked to read the written feedback and respond to it through comments using the commenting function of Google Docs and do text revisions using highlights, which the instructor would easily track across the drafts later. The process of feedback and students' responding to feedback continued till the 13th week when students were asked to finalize their assignments as final drafts that would be submitted to the instructor via the re-assignment submission of the university course.

\section{Figure 2}

Sample Print Screen Shot of the E-Feedback and Student's Response to it through Google Docs.

\begin{abstract}
Igularity. If there are more than one cat, a plural marker -s must be attached to the root word cat, thus z new word cats. The plural marker cannot stand on its own. It is is only meaningful if it is attached to other independent morpheme. In other words, this process is known as inflectional morpheme as it anges the function of the word and not the word class. Another process is known as derivational lereby the word changes meaning or the word class when attached to another morpheme (Denham Lobeck, 2013). For instance, when arrange (verb) is attached to the suffix -ment, it becomes angement (noun). The word class transition can be seen from a verb to a noun due to the affixation xess that takes place. However, there are exceptions. Words such as put-put and cut-cut are known have zero morphemes due to the fact they are not required to take place with other morphemes to ficate the past tense. Irregular verbs such as buy-bought, run-ran and swim-swam are also known as eration in their tenses. There are nine other processes such as conversion, coinage, reduplication $d$ the such to be a part of morphology.
\end{abstract}

Syntax, on the other hand, requires one to understand how constituents are arranged to form phrase or a complete sentence (Yule, 2014). It is also a system of rules and principles that depicts

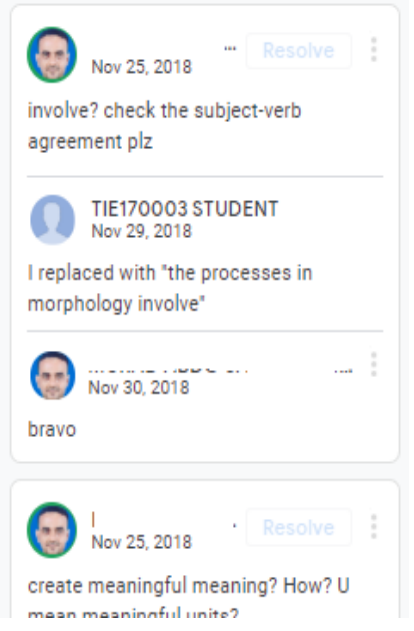

\section{Data Collection and Analyses}

The data was collected from four primary sources: instructor's e-feedback questioning in the form of Google Docs written comments, students' responses to e-feedback in written comments through Google Docs, students' text revisions as changes through changes Google Docs and follow-up interviews. However, we excluded the follow-up interviews from our analyses within the focus of the study reported in this paper and its length.

The data analysis was initiated by coding the efeedback questioning. Each e-feedback question was coded, analyzed, and categorized based on the analytical frameworks adopted from the literature review on teacher feedback. The first stage involved coding each question concerning its form: whether it is a Yes/No question or a Wh-question. During this 
stage, we observed single written comments carrying out a combination of questions each, and therefore, we came up with a third category, labeled as combined questions.

Some researchers (Ferris, 1997; Hyland \& Hyland, 2001) emphasized the need for feedback coders to distinguish the various functions of questions. Therefore, the second stage of e-feedback questioning coding focused on identifying the various patterns of language functions of e-feedback questioning. So each form of the questions mentioned above was coded concerning the function it was intended to perform by the instructor. Based on our coding, several functions were identified for each form of the e-feedback question (Appendix 1).

Then, students' responses to e-feedback questions through the reply functions of Google Docs and edits through the history of their drafts were identified and analyzed. Initially, our focus was on students' responses to the e-feedback through written comments and their text revisions. For the commenting responses, each student's reply to the feedback was analyzed in terms of its function based on codes adopted from a few studies on students' commenting responses to feedback (e.g., Alharbi, 2019; Alvarez et al., 2012; Chong, 2019). Other comments that did not suit these codes were inductively coded (Appendix 2). Moreover, students' text revisions tracked through highlights and suggested edits of the Google Docs pages were coded in terms of its foci (e.g., content, organization, and so forth) according to the foci of e-feedback (Appendix 3).

However, during this stage of coding students' responses to the e-feedback questioning, we also identified other actions taken by students in responding to e-feedback: interacting around the feedback issues through threads of comments (interacting with each other and interacting with the course instructor), seeking feedback and resolving the e-feedback. Commenting on the e-feedback (a single comment) was noticed in responding to eliciting an answer or detailed information, whereas interacting on the feedback occurred because students failed to understand the e-feedback questions, which created threads of comments responses. The e-feedback resolving responses were observed when the students had already addressed issues in the assignments through text revisions and were not required to comment on the e-feedback through clarifications or explanations. Samples of these patterns of responses are provided in the finding section.

The final stage of data analysis focused on counting the overall numbers of the categories mentioned above and sub-categories of teacher's efeedback questions and students' responses to questions via Google Docs. This also focused on determining students' uptake of the instructor's questioning feedback by cross-referencing the various types of students' text revisions to the number of e-feedback questions.

To avoid any biases and achieve high interrater reliability, an additional researcher, a lecturer of English, was also invited to the Google Docs pages to start data analysis earlier before the data collection was completed. As a result, the entire data analysis process was iterative and the inter-coder agreement reached was $77.51 \%$. However, after several meetings and discussions, most of the discrepancies were resolved, and the percentage of the agreement reached $81 \%$.

\section{FINDINGS}

Patterns of Instructor's e-Feedback Questioning Our analysis of the instructor's questions in efeedback (Appendix1) illustrates that the instructor composed his questions in the form of three main categories: single Yes/No questions, single Whquestions, and a combination of both forms. As revealed by our simple counting of these three categories of forms of questions (Table 2), it is evident that overall, single Yes/No questions scored as the highest or most frequently form of questions used by the instructor (152), followed by single Whquestions (107) and finally, combined Yes/No and Wh-questions (105).

Table 2

Calculations of The Types of Instructor's EFeedback Questioning

\begin{tabular}{lll}
\hline Patterns & Intentions & Total \\
\hline Single Yes/No & Checking intentions & 40 \\
questions & Eliciting a correct & 33 \\
& response/revision & \\
& Checking understanding & 32 \\
& Checking certainty & 27 \\
& Requesting & 20 \\
& Total of category & 152 \\
Single Wh- & Eliciting information & 27 \\
questions & Seeking justifications & 24 \\
& Seeking clarifications & 24 \\
& Seeking evaluations & 22 \\
& Seeking elaborations & 10 \\
& Total of category & 107 \\
Combined & Seeking clarification + & 14 \\
questions & checking intention & \\
& Seeking justifications + & 13 \\
& checking certainty & \\
& Checking certainty + & 16 \\
& seeking justifications & 12 \\
& Eliciting information + & \\
& checking intention & 55 \\
Overall & Total of category & 314 \\
\hline & Overall &
\end{tabular}

The three categories of questions served as pragmatic acts used by the instructor for various communication purposes/needs. The Yes/No 
questions appeared to serve as checking, eliciting, and requesting, with checking students' intentions as the highest function (40) and requesting as the lowest function (20). However, the W-h questions seemed to allow the instructor to elicit information from the students and seek their clarifications, justifications, evaluations, and even elaborations of specific ideas and points in their writing. Thus, the instructor could combine two different pragmatic functions in a single written comment according to the communication needs of e-feedback contexts by using combined questions. The combination of checking certainty and seeking justifications was most frequently used, while the combination scoring the lowest number of occurrences (12) elicits and checks information.

\section{The Role of Questioning in Promoting Learners' Responses to and Use of e-Feedback}

From our qualitative analysis of students' responses, questioning plays a role in engaging learners in actively responding to e-feedback in several ways: (1) commenting on the e-feedback, (2) interacting around the e-feedback issues, (3) seeking efeedback, and (4) resolving the e-feedback through the resolve function of Google Docs. Table (3) provides samples demonstrating the four categories of responses to feedback. It should be noted that the first category reflects feedback demanding students' responses in a single comment, and the second category shows how students interact with the instructor to resolve ambiguities. The third category displays students' imitations of interaction with the instructor. However, the fourth category demonstrates that the learners had already addressed the issue in their writing by revising it, and there was no need to comment on the question, especially if the question required the learner to revise the text rather than to clarify a particular idea or point in the text.

In using the e-feedback questioning, learners, through Google Docs, could vary their strategies in editing and making their edits visible to the instructor from highlighting the new changes in a different font, using a bold font to suggested edits of Google Docs. As illustrated by Appendix (3), these revisions addressed issues varying from content and idea development and organization to minor issues, such as accurate language and misspelling and punctuations and formatting issues.

Table 3

Samples of Patterns of Students' Responses to the E-Feedback Questioning Through Google Docs

\begin{tabular}{ll}
\hline Patterns of responses to e-feedback & Samples \\
\hline Commenting on the feedback & Teacher A shape of what? Not language? Or here, do you mean in its general \\
& definition? \\
& TIE140011 STUDENT yes, we mean in general.
\end{tabular}

Interacting around the feedback Teacher, why AdjP? U have the NP "Two mice," so Det+ N?

issues TIE170011, so the 'two' is considered as a determiner?

Teacher, What do you think?

TIE170011 STUDENT I think it's a determiner.

Teacher, yes, it is a determiner and great for you.

Teacher, why are there tables and graphs?

TIE130011 better out this table in the data section as you already have the bar graphs for the results. Right?

TIE120011, for me, is better put the table with the graphs. What do you think?

TIE130011 ok, if you put the tables here, then what are you going to put in the data section?

TIE120011 Yes, now we got the teacher's feedback above and agree with you.

Seeking further feedback

TIE190011 Dr. Can you give us your feedback, especially on the syntax analysis of our paper that we revised?

Teacher, sure I will do.

TIE190011 Thank you, Dr.

Resolving the feedback

Teacher selected text: and or \& here?

TIE150011 Reply•Resolve

\section{The Effect of Teacher's Formulation of e- Feedback Questioning on Students' Responses and Use/Uptake of e-Feedback}

As illustrated in Table (4), the teacher's formulation of e-feedback questioning affects students' overall level of processing the e-feedback. Yes/No questions promoted the highest number of students' responses to e-feedback (148). This is followed by the use of single Wh-questions, whereas combined questions had the lowest effect on students' processing of the e-feedback. Most of the students' commenting on the e-feedback and resolving the efeedback were promoted by Yes/No questions. On the other hand, most students' interactions around 
the feedback were fostered by single Wh-questions and combined questions, and most of their responses seeking further feedback were promoted by the teacher's use of single Wh-questions.

Table 4

Cross-Referencing of Students' Responses to E-Feedback Questioning Formulations

\begin{tabular}{lccc}
\hline Patterns & Single Yes/No questions & Single Wh-questions & Combined questions \\
\hline Commenting on the feedback & 100 & 29 & 12 \\
Interacting around the feedback & 4 & 21 & 23 \\
Seeking further feedback & 9 & 19 & 6 \\
Resolving the feedback & 35 & 21 & 1 \\
Overall & 148 & 90 & 42 \\
Ignoring e-feedback & 4 & 17 & 13 \\
\hline
\end{tabular}

The way the teacher formulated his e-feedback questioning had also an influence on students' overall use/uptake of feedback as single Yes/No questions led to the highest proportion of students' text revisions (109), followed by single Whquestions (89) and combined questions (44) (Table
5). Results also show while most of the text revisions on content and organization were attributed to teacher's single Wh-questions, the most significant proportions of text revisions focusing on language and requirements resulted from the teacher's use of single Yes/No questions.

Table 5

Students' Uptake/Use of the Various Types of E-Feedback Questioning

\begin{tabular}{lccc} 
Patterns & Single Yes/No questions & Single Wh-questions & Combined questions \\
\hline Content & 29 & 72 & 28 \\
Organization & 1 & 5 & 3 \\
Language & 72 & 10 & 10 \\
Requirements & 7 & 2 & 3 \\
Overall & 109 & 89 & 44 \\
Ignoring e-feedback & 43 & 18 & 11 \\
\hline
\end{tabular}

This result explains how the instructor varied his questions according to the nature of the issue(s) and error(s) that needed to be addressed through feedback questioning. For example, while microlevel issues related to language and requirement seem easy to address through Yes/No questions, macro-level issues related to content and idea development and organization may require the instructor's use of single Wh-questions and combined questions that seek higher or more complex responses from learners (e.g., learners' clarifications or explanations of their intended ideas in the texts).

\section{DISCUSSION}

In responding to the recent call for teacher practice that fosters ESL/EFL writing (Carlessa \& Boud, 2018; Ferris, 1995; Goldstein, 2006; Jonsson, 2013; Storch \& Wigglesworth, 2010), the current study focused on instructor's formulations of e-feedback in the form of questioning through Google Docsbased comments. Feedback formulation, being the first stage in the interactive e-feedback process through Google Docs (Figure 2), during this stage, the instructor formulated his feedback questioning in three different forms: single Yes/No questions, single Wh-questions, and combined questions. While Yes/No questions serve as a way to elicit responses and corrections from students, checking their certainty about their ideas and language use in their assignments, checking their understanding, and requesting them to carry out particular text revisions, Wh-questions function as eliciting information and seeking learners' clarifications, justifications/explanations, evaluations and even elaborations of ideas. Similarly, results of some earlier studies (Ferris, 1997; Hyland \& Hyland, 2001; William, 2004) and e-feedback (Alharbi, 2019; Alvarez et al., 2012; Wolsey, 2008) have identified some functions of teacher's use of questions, including eliciting responses, clarifications, and explanations. Our study also contributes to this evidence by delving into more specific functions of teacher questions. What is interesting is the instructor's combined questions (e.g., seeking clarification + checking intention). The varying frequency of using these three forms of questions suggests the instructor's varying intentions conveyed through questions depending on the nature of issues in students' written assignments.

With the increasingly raised questions on how teachers should foster students' responses to feedback (e.g., Boud \& Molloy, 2013; Carless \& Boud, 2018; Ene \& Upton, 2014; 2018; Goldstein, 2006; Storch \&Wigglesworth, 2010), this study supports the role of questioning in eliciting students' active responses to feedback (Ene \& Upton, 2018; Tuzi, 2004). However, what responses feedback can elicit from students before revising their texts has not been fully explored in earlier research. Here comes the contribution of the current study by 
offering evidence on learners' various strategies in processing or understanding the e-feedback: commenting on the e-feedback (e.g., clarifying their intentions, evaluating feedback, and so on), interacting with the instructor and with each other to resolve misunderstanding and confusion and even seeking feedback on particular aspects of their texts rather than acting as mere receivers of teacher feedback. This particular finding supports the current argument that learners should be active in the process (Henderson et al., 2019). It is also in line with Schillings et al. (2019) that learner-learner dialogue enhances students' understanding of teacher feedback.

The above finding also highlights the role of Google Docs in providing learners the opportunity to interact around the feedback issues. It is only through interacting around feedback issues that feedback dissonances are resolved (Carless, 2020). Google Docs facilitates the creation of threads of comments attached to a particular feedback commentary. It is only through interaction that students can comprehend the intent of feedback. Google Docs also allowed students to respond to the e-feedback by resolving the feedback, which, as reported in a few studies (Alharbi, 2019; Bradley \& Thouësny, 2017), does not mean that learners were passive or they ignored the e-feedback. However, by resolving the e-feedback, those students were trying to hint that a particular feedback questioning requesting them to revise their text had been already addressed through text revision(s) in their assignments. In other words, most of those questions resolved were observed to be questions requesting students to make specific text revisions (e.g., Can you change this word?) rather than eliciting information, seeking clarification, or asking students to explain ideas in their assignments. So students were not required to comment on these questions.

Using the e-feedback, students also revised their texts through Google Docs by highlighting the changes made to their texts and even using suggested edits. Such findings corroborate findings of earlier studies on the editing facilitative features of Google Docs (Holliman \& Scanlon, 2006; Oishi, 2007; Suwantarathip \& Wichadee, 2014; Perron \& Sellers, 2011). Moreover, students focused most of the text revisions on content and idea development, while the least focused on both organization and requirements in their assignments. This suggests that e-feedback positively affects students' macro-level or meaning-level text revisions, such as content (Ene \& Upton, 2018; Tuzi, 2004).

In answering the third research question about the extent to which teachers' formulations of efeedback, questioning influence undergraduates' processing and use/uptake of feedback in revising their writing, exciting results were obtained. First, we found that the way the teacher formulated his efeedback questioning influenced students' overall number of responses to e-feedback. Second, the students' types of responses to e-feedback were influenced by the teacher's formulations of questioning. While most of students' two types of responses: commenting on the e-feedback and resolving it, were associated with Yes/No questions, most of their other two types of responses: interacting around the feedback and seeking further feedback, were promoted by the use of combined questions and single Wh-questions, respectively.

Learners' use/uptake of feedback is also influenced by the types of feedback (Ene \& Upton, 2018; Fu \& Nassaji, 2016). Similarly, in this study, the way e-feedback questioning is formulated influences the extent to which students used efeedback in revising their assignments. For example, while Yes/No questions resulted in the highest overall number of text revisions, combined questions led to the lowest overall number of text revisions. Furthermore, most of the text revisions focusing on content and organization were attributed to the teacher's use of single Wh-questions. In contrast, most of their text revisions focusing on language and requirements were associated with the use of single Yes/No questions.

In comparing the overall number of feedback questioning to the overall number of text revisions, there will be a small number of questions that students did not address. This suggests that some students either failed to act successfully upon some e-feedback because of their lacking or deficit repertoire of revising strategies or were unwilling to use feedback in revising their texts. Therefore, students should be trained on how to revise their writing through explicit instruction. Their lack or deficit revision strategies may hinder their productive use of feedback (Winstone et al., 2017; Carless \& Boud, 2018) and should be motivated to respond to feedback actively.

\section{CONCLUSION}

The present study explored the role of teacher Google Doc-based feedback given in the form of questions on the assignments of 14 pairs of undergraduates in a Malaysian university in fostering their responses to feedback and uptake of it in writing. The findings of the study revealed that the feedback questions fall into single Yes/No questions, single Wh-questions, and a combination of both, which served as eliciting responses, eliciting information, seeking clarifications, requesting, checking certainty, and inviting learners to respond to and interact over the e-feedback before using it in revising their texts. In addition, findings indicate that Google Docs functions as an interactive platform where students diversify their responses to e-feedback from commenting on the e-feedback, interacting around the e-feedback issues, seeking further feedback, resolving the e-feedback, and 
addressing the e-feedback through edits/text revisions.

The current study offers useful instructional implications for writing teachers and instructors in enhancing feedback practices in writing courses. First, the study argues that teacher feedback should be composed in a way that promotes learners' responses to and interaction around it. Second, since current research calls for cultivating learners' roles in the process of feedback, this study provides evidence on how teacher feedback questioning played a role in shifting learners' roles from passive receivers to active respondents to teacher feedback. Third, as learners may also find it challenging to understand one-way-directional feedback, it becomes necessary for teachers to think of effective instructional strategies in giving learners feedback, which enables them to respond, react, and resolve their misunderstanding of feedback information. In this regard, through evidence of learners' various comments on feedback, the study supports questioning as an effective strategy in providing feedback on writing if the goal is to encourage learners to negotiate the feedback and clarify their intentions. Interestingly, as learners are offered the opportunity to articulate their voices about the teacher feedback received, they are more likely to enhance their understanding of it and, consequently, increase their successful use or uptake of it in revising their texts.

Despite the encouraging findings of the study, several limitations should be addressed for future research. First, our investigation of e-feedback focused on the feedback provided by one instructor. Therefore, future research should focus on the efeedback questioning of several instructors to find out how formulations of feedback questioning may differ among instructors. Another possible and valuable aspect of research for future investigations is to explore how Google Docs influences the way instructors formulate their e-feedback and how students respond to e-feedback by comparing it against another tool to understand better the contextual factors affecting e-feedback formulation and students' responses to e-feedback.

In this study, students' responses to e-feedback partially reflect how they process and understand the e-feedback before using it in their writing. Future research may also use students' recorded reflection on the feedback to articulate their reactions (effective engagement) because such feelings can be private and fluctuating. Thus, their written responses to e-feedback may not reveal their genuine feelings/emotions. Follow-up interviews can also be used to support analyses of students' actual responses and their recorded reflection on efeedback.

\section{ACKNOWLEDGEMENTS}

The authors would like to thank the undergraduates participating in this study and the Faculty of Language and Linguistics staff who have contributed to this study.

\section{REFERENCES}

AbuSeileek, A., \& AbuAlsha'r, A. (2014). Using peer computer-mediated corrective feedback to support EFL learners' writing. Language Learning \& Technology, 18(1), 76-95.

Alharbi, M. A. (2019). Exploring the potential of Google Doc in facilitating innovative teaching \& learning practices in an EFL writing course. Innovation in Language Learning and Teaching, 1-16. https://doi.org/10.1080/17501229.2019.157215 7

Alsolami, E. H., \& Elyas, T. (2016). Investigating teachers' corrective feedback \& learners' uptake in the EFL classrooms. International Journal of Educational Investigations, 3(1), 115-132.

Alvarez, I., Espasa, A., \& Guasch, T. (2012). The value of feedback in improving collaborative writing assignments in an online learning environment. Studies in Higher Education, 37(4), 387-400. http://dx.doi.org/10.1080/03075079.2010.5101 82

Boud, D., \& Molloy, E. (2013). Rethinking models of feedback for learning: the challenge of design. Assessment and Evaluation in Higher Education, 38(6), 698-712. http://dx.doi.org/10.1080/02602938.2012.6914 62

Bradley, L., \& Thouësny, S. (2017). Students' collaborative peer reviewing in an online writing environment. Themes in Science \& Technology Education, 10(2), 69-83.

Carless, D. (2020). Longitudinal perspectives on students' experiences of feedback: A need for teacher-student partnerships. Higher Education Research and Development, 1-14. http://dx.doi.org/10.1080/07294360.2019.1684 455

Carless, D., \& Boud, D. (2018). The development of student feedback literacy: Enabling uptake of feedback. Assessment and Evaluation in Higher Education, 43(8), 1315-1325. https://doi.org/10.1080/02602938.2018.146335 4

Chong, S. W. (2019). College students' perception of e-feedback: A grounded theory perspective. Assessment and Evaluation in Higher Education, 44(7), 1090-1105. https://doi.org/10.1080/02602938.2019.157206 7 
Cramp, A. (2011). Developing first-year engagement with written feedback. Active Learning in Higher Education, 12(2), 113-124. https://doi.org/10.1177\%2F146978741140248 4

Cunningham, K. J. (2019). Student perceptions and use of technology-mediated text \& screencast feedback in ESL writing. Computers \& Composition, 52, 222-241. http://doi.org/10.1016/j.compcom.2019.02.003

Duijnhouwer, H., Prins, F. J., \& Stokking, K. M. (2012). Feedback providing improvement strategies and reflection on feedback use: Effects on students' writing motivation, process and performance. Learning \& Instruction, 22, 171-184.

https://doi.org/10.1016/j.learninstruc.2011.10.0 03

Ene, E., \& Upton, T. A. (2014). Learner uptake of teacher electronic feedback in ESL composition. System, 46, 80-95. http://doi.org/10.1016/j.system.2014.07.011

Ene, E., \& Upton, T. A. (2018). Synchronous and asynchronous teacher electronic feedback and learner uptake in ESL composition. Journal of Second Language Writing, 41, 1-13. https://doi.org/10.1016/j.jslw.2018.05.005

Ferris, D. R. (1995). Student reactions to teacher response in multiple-draft composition classrooms. TESOL Quarterly, 29, 33-53. https://doi.org/10.2307/3587804

Ferris, D. R. (1997). The influence of teacher commentary on student revision. TESOL Quarterly, 31(2), 315-339. https://doi.org/10.2307/3588049

Fu, T., \& Nassaji, H. (2016). Corrective feedback, learner uptake, \& feedback perception in a Chinese as a foreign language classroom. Studies in Second Language Learning and Teaching, 6(1), 159-181. http://doi.org/10.14746/ssllt.2016.6.1.8

Gielen, S., Peeters, E., Dochy, F., Onghena, P., \& Struyven, K. (2010). Improving the effectiveness of peer feedback for learning. Learning \& Instruction, 20, 304-315. http://doi.org/10.1016/j.learninstruc.2009.08.0 07

Gielen, S., Tops, L., Dochy, F., Onghena, P., \& Smeets, S. (2010). A comparative study of peer and teacher feedback and of various peer feedback forms in a secondary writing curriculum. British Educational Research Journal, 36, 143-162. http://doi.org/10.1080/01411920902894070

Goldstein, L. (2006). Feedback and revision in second language writing: Contextual, teacher, and student variables. Feedback in Second Language Writing: Contexts \& Issues, 185205.
https://doi.org/10.1017/CBO9781139524742.0 12

Henderson, M., Phillips, M., Ryan, T., Boud, D., Dawson, P., Molloy, E., \& Mahoney, P. (2019). Conditions that enable effective feedback. Higher Education Research \& Development, 38(7), 1401-1416. https://doi.org/10.1080/07294360.2019.165780 7

Holliman, R., \& Scanlon, E. (2006). Investigating cooperation and collaboration in near synchronous computer-mediated conferences. Computers \& Education, 46(3), 322-335.

Hyland, F., \& Hyland, K. (2001). Sugaring the pill: Praise and criticism in written feedback. Journal of Second Language Writing, 10(3), 185-212. https://doi.org/10.1016/S1060$3743 \% 2801 \% 2900038-8$

Jeong, K. O. (2016). A study on the integration of Google Docs as a web-based collaborative learning platform in EFL writing instruction. Indian Journal of Science \& Technology, 9(39), 1-7. http://dx.doi.org/10.17485/ijst/2016/v9i39/103 239

Jonsson, A. (2013). Facilitating productive use of feedback in higher education. Active Learning in Higher Education, 14(1), 63-76. https://doi.org/10.1177\%2F146978741246712 5

McConlogue, T. (2015). Making judgments: Investigating the process of composing and receiving peer feedback. Studies in Higher Education, 40(9), 1495-1506. https://doi.org/10.1080/03075079.2013.868878

Munje, P. N., Nanima, R. D., \& Clarence, S. (2018). The role of questioning in writing tutorials: A critical approach to student-centered learning in peer tutorials in higher education. Mentoring \& Tutoring: Partnership in Learning, 26(3), 336-353. https://doi.org/10.1080/13611267.2018.151195 3

Nassaji, H. (2011). Correcting students' written grammatical errors: The effects of negotiated versus non negotiated feedback. Studies in Second Language Learning \& Teaching, 1(3), 315-334. https://doi.org/10.14746/ssllt.2011.1.3.2

O’Sullivan, I., \& Cleary, L. (2014). Peer-tutoring in academic writing: The infectious nature of engagement. Journal of Academic Writing, 4(1), 52-65. https://doi.org/10.18552/joaw.v4i1.72

Oishi, L. (2007). Working together: Google APPS goes to school. Technology \& Learning, 27(9), 46-47.

Perron, B., \& Sellers, J. (2011). A review of the collaborative \& sharing aspects of Google 
Docs. Research on Social Work Practice, 21, 489-490.

Robinson, S., Pope, D., \& Holyoak, L. (2013). Can we meet their expectations? Experiences and perceptions of feedback in first-year undergraduate students. Assessment and Evaluation in Higher Education, 38(3), 260272. https://doi.org/10.1080/02602938.2011.629291

Rodina, H. (2008). Paperless, painless: Using MS Word tools for feedback in writing assignments. The French Review, 106-116.

Saeed, M. A., \& Al Qunayeer, H. S. (2020).

Exploring teacher interactive e-feedback on students' writing through Google Docs: factors promoting interactivity and potential for learning. The Language Learning Journal, 118. http://doi.org/10.1080/09571736.2020.178671 1

Saeed, M. A., Al Qunayeer, H. S., \& AL-Jaberi, M. A. (2021). Exploring supervisory feedback formulation on academic writing of research proposals and postgraduates' responses to feedback: A case study. SAGE Open, 11(2), 115.

https://doi.org/10.1177\%2F215824402110071 25

Schillings, M., Roebertsen, H., Savelberg, H., Whittingham, J., \& Dolmans, D. (2019). Peerto-peer dialogue about teachers' written feedback enhances students' understanding of how to improve writing skills. Educational Studies, 46, 1-15. https://doi.org/10.1080/03055698.2019.165169 2

Schindler, L., \& Burkholder Jr, G. J. (2014). Instructional design and facilitation approaches that promote critical thinking in asynchronous online discussions: A review of the literature. Higher Learning Research Communications, 4(4), 11-29. http://doi.org/10.18870/hlrc.v4i4.222

Stake, R. E, (1995). The art of case study research. Sage.
Storch, N., \& Wigglesworth, G. (2010). Learners' processing, uptake and retention of corrective feedback on writing: Case Studies. Studies in Second Language Acquisition, 32(2), 303-334. http://dx.doi.org/10.1017/S0272263109990532

Suwantarathip, O., \& Wichadee, S. (2014). The effects of collaborative writing activity using Google Docs on students' writing abilities. Turkish Online Journal of Educational Technology-TOJET, 13(2), 148-156.

Tuzi, F. (2004). The impact of e-feedback on the revisions of L2 writers in an academic writing course. Computers \& composition, 21(2), 217235.

William, J. (2004). Tutoring and revision: Second language writers in the writing center. Journal of Second Language Writing, 13(3), 173-201. http://doi.org/10.1016\%2Fj.jslw.2004.04.009

Winder, R., Kathpalia, S. S., \& Koo, S. L. (2016). Writing centre tutoring sessions: addressing students' concerns. Educational Studies, 42(4), 323-339. https://doi.org/10.1080/03055698.2016.119347 6

Winstone, N. E., Nash, R. A., Rowntree, J., \& Parker, M. (2017). 'It'd be useful, but I wouldn't use it': barriers to university students' feedback-seeking and recipience. Studies in Higher Education, 42(11), 20262041.

Wolsey, T. (2008). Efficacy of instructor feedback on written work in an online program. International Journal on E-learning, 7(2), 311329. https://doi.org/10.1080/03075079.2015.113003 2

Xu, L. (2017). Written feedback in intercultural doctoral supervision: a case study. Teaching in Higher Education, 22(2), 239-255. http://doi.org/10.1080/13562517.2016.123748 3

Zhou, W., Simpson, E., \& Domizi, D. P. (2012). Google Docs in and out-of-class collaborative writing activity. International Journal of Teaching \& Learning in Higher Education, 24(3), 359-375. 


\section{Appendix A}

Sample Coded E-Feedback Questioning

\begin{tabular}{|c|c|c|}
\hline Patterns & Intentions & Total \\
\hline \multirow{5}{*}{$\begin{array}{l}\text { Single Yes/No } \\
\text { questions }\end{array}$} & Checking intentions & Do you mean "Those prepositional phrases can be? \\
\hline & Eliciting a correct response/revision & has? \\
\hline & Checking understanding & So have you got me? \\
\hline & Checking certainty & Are you sure that this is a clause here? \\
\hline & Requesting & $\begin{array}{l}\text { Can you re-write it by starting the sentence with "They } \\
\text { will also be selected based"? }\end{array}$ \\
\hline \multirow[t]{5}{*}{ Single Wh-questions } & Eliciting information & Who are the native speakers here in this sentence? \\
\hline & Seeking justifications & Why did you put this as a noun? \\
\hline & Seeking clarifications & What do you mean by this sentence? \\
\hline & Seeking evaluations & What do you think about these three sentences? \\
\hline & Seeking elaborations & $\begin{array}{l}\text { What about adding more sentences on the syntactic } \\
\text { features of English in your introduction? }\end{array}$ \\
\hline \multirow[t]{4}{*}{ Combined questions } & $\begin{array}{l}\text { Seeking clarification }+ \text { checking } \\
\text { intention }\end{array}$ & $\begin{array}{l}\text { What do you mean by this? Do you mean you will } \\
\text { analyze it in terms of morphological features? }\end{array}$ \\
\hline & $\begin{array}{l}\text { Seeking justifications }+ \text { checking } \\
\text { certainty. }\end{array}$ & Why is it a determiner? Are you sure? \\
\hline & $\begin{array}{l}\text { Checking certainty }+ \text { seeking } \\
\text { justifications }\end{array}$ & Is? Why is it here? \\
\hline & $\begin{array}{l}\text { Eliciting information }+ \text { checking } \\
\text { intention }\end{array}$ & Syntactic what? Do you mean features or rules? \\
\hline
\end{tabular}

\section{Appendix B}

Sample Coded Students' Commenting on the E-Feedback Questioning

\begin{tabular}{|c|c|c|}
\hline Type & Sub-types & Example \\
\hline \multirow[t]{11}{*}{$\begin{array}{l}\text { Commenting } \\
\text { on feedback }\end{array}$} & Certainty vs. Uncertainty & $\begin{array}{l}\text { Yup, Dr. I am sure about this. } \\
\text { I'm not really sure about this, Dr. }\end{array}$ \\
\hline & Error admission & I have just realized that I made those silly mistakes. \\
\hline & Informing of making revisions & $\begin{array}{l}\text { Okay. I have included } 3 \text { and tried to make connections with the } \\
\text { challenges that I mentioned and the citations that I have used. }\end{array}$ \\
\hline & Willingness to make corrections & $\begin{array}{l}\text { I will try and come up with something to sum up, what we have } \\
\text { done. }\end{array}$ \\
\hline & Questioning & Is it correct now Dr.? \\
\hline & & May I know where I should put the clauses? \\
\hline & Misunderstanding & Yup, I got what u mean, the COMP 'that' is missing. \\
\hline & Confirming intended meaning & Yes, Dr. This is exactly what I meant. \\
\hline & Clarification/reasoning & $\begin{array}{l}\text { I mean, maybe add it in a bracket, indicating that it should be there } \\
\text { after 'believed.' }\end{array}$ \\
\hline & Confusion & $\begin{array}{l}\text { I mean, I am confused with when should I take it as an advP rather } \\
\text { than a PP! }\end{array}$ \\
\hline & Providing a correct/incorrect form & This is the corrected version of No.4 sentence. \\
\hline
\end{tabular}




\begin{abstract}
Appendix C
Sample Students' Coded Text Revisions

C.1 Content-related text revisions

First Draft: Here are four of the most well-known linguistic schools of thought; Traditional grammar, Generative grammar, Systemic functional grammar, and Pattern grammar. This paper aims to provide a critical review of three approaches.

Revised Draft: However, the aim of this paper is to provide a critical review of three approaches which are Traditional grammar, Generative grammar, and Systemic Functional grammar.
\end{abstract}

\section{C.2 Organization-Related Text Revisions}

Revised Draft Using Track Change in Re-ordering the Ideas in the Introduction: Morphology and syntax are parts of the linguistic branches. Other branches include phonetics and phonology, semantics, and pragmatics. Morphology can be defined as the study of how words are structured. It is the internal construction of words. In a more simplified explanation, morphology is the study of word-formation. Syntax, on the other Han, is the study of how phrases and sentences are structured. What distinguishes morphology and syntax is that morphology is concerned with the structure of words, while syntax is concerned about the structure of phrases and sentences. In this assignment, we will analyze morphology and syntax based on the data chosen. The data that we have chosen is Harry Potter and the Philosopher's Stone: Chapter 9 (page
113-115). Harry Potter is a series of fantasy fiction novels written by JK Rowling. Morphology and syntax are parts of the linguistic branches. Other branches include phenetics and phonology, semanties, and pragmatics. Morphology can be defined as the stuly of how words are structured. It is the internal construction of words. In a more simplified explanation, morphology is the stuly of word-formation. Syntax, on the other Han, is the study of how phrases and sentences are structured. What distinguishes merphology and syntax is that merphelogy is concerned with the structure of words, while syntax is concerned about the structure of phrases and sentences.

\section{C.3 Language-Related Text Revisions}

First Draft: The second feature of this grammar is Traditional Grammar only analyses the written form of the language.

Revised Draft: The second feature of this grammar is that Traditional Grammar only emphasizes the written form of the language.

\section{C.4 Requirement-Related Text Revisions}

First draft: (Schmid H. J. 2012) mentioned that linguistic theories are formed to comprehend the nature and structure of a language in terms of grammar.

Second Draft: Schmid (2012) mentioned that linguistic theories are formed to comprehend the nature and structure of a language in terms of grammar. 